\title{
A prospective study of peripheral blood DNA methylation at RPTOR, MGRN1 and $R A P S N$ and risk of breast cancer
}

Pierre-Antoine Dugué ${ }^{1}$, Roger L. Milne ${ }^{1,2}$ and Melissa C. Southey ${ }^{2}$

${ }^{1}$ The Cancer Council Victoria and ${ }^{2}$ The University of Melbourne, Victoria, Australia.

A recent report by Tang et al. contributes to a rapidly emerging and exciting field of work examining blood-derived DNA methylation as a risk factor for breast cancer [1]. Multiple studies have identified associations with increased breast cancer risk for a genome-wide measure of hypomethylation in blood-derived DNA [2, and others]. Tang et al. carried out a considered, staged analysis that involved a genome-wide discovery phase using the Illumina Infinium HumanMethylation 450K methylation assay and blood-derived DNA from 48 unselected breast cancer cases and 48 unaffected controls. They then measured seven marks that were suitable for analysis using MassARRAY Epityper technology in three validation cohorts that included blood-derived DNA from a proportion of familial breast cancer cases. Associations with risk were replicated for three marks. For these three replicated marks, the total number of cases included was between 565 and 568. The authors noted the importance of replicating their findings in prospective studies.

We attempted to replicate the findings of Tang et al. using a prospective design based on 423 breast cancer cases and matched unaffected controls participating in the Melbourne Collaborative Cohort Study (MCCS). MCCS participants provided a blood sample at baseline (1990-94) and incident cases to 31 December 2007 were identified through linkage with the Victorian Cancer Registry. Controls were selected through incidence density sampling and individually matched to cases on year of birth, year of baseline attendance, country of origin and sample type. Case-control pairs were allocated consecutively on a same chip of the assay to minimise batch effects [2]. We used conditional logistic regression to compute odds ratios (OR) and 95\% confidence intervals (CI) for the association between methylation level at each $\mathrm{CpG}$ (expressed as M-values, per standard deviation) and risk of breast cancer. We found no evidence that any of the three $\mathrm{CpG}$ sites identified and replicated in the Tang et al. study were associated with risk of breast cancer in our prospective study (Table 1). This was the case in analyses with and without adjustment for cell composition (estimated using the Houseman algorithm) and after restricting the analysis to cases diagnosed within five years of blood draw. Further, there was no evidence of an interaction with time since blood draw, fitted as a 
continuous variable (Table 1). Adjusting for smoking status, body-mass index and alcohol drinking did not substantially change these findings. No evidence of association was observed $(\mathrm{P} \geq 0.1)$ for the additional four $\mathrm{CpGs}$ identified in the discovery phase of the Tang et al. study that were not replicated in later phases of that study. All seven CpGs were measured with very good reliability in our study (based on 15 technical replicate pairs, intraclass correlation coefficients were typically greater than 0.85 , except $\operatorname{cg} 21932542$ for which ICC was $0.68[3])$.

The main difference between our study and that of Tang et al. is the fact that our blood samples were taken from unaffected individuals whereas Tang et al. used samples taken after breast cancer diagnosis. We found no evidence of varying effect size by time since blood draw, nor of hypomethylation in cases for blood samples taken within five years of diagnosis (although power was limited for these subgroup analyses). Blood samples drawn at the time of breast cancer diagnosis may contain circulating tumour cells and or cfDNA, both of which can make a significant contribution to the DNA yield especially in the context of heavy tumour load. Although in another context it is exciting to consider the measurement of blood born tumour DNA methylation marks, this is a complication for studies aiming to identify risk factors for unaffected women. Indeed, these marks could have considerable potential as biomarkers for residual disease monitoring.

Another difference between the two studies is that MCCS cases and controls were matched on age and the time period of blood sample collection, which was wider and heterogeneous in the German study. We also controlled more strictly for batch effects by randomly assigning each case-control pair to the same batch [3]. The methylation measurement technology used in the two studies was also different; interestingly, only 5 of the 7 marks identified in the discovery phase of Tang et al. passed the technical replication phase using MassARRAY Epityper (on the same 94 DNA samples). Tang et al. also used a mix of sporadic and familial cases compared to the population-based sample from the MCCS, although this did not seem to have affected their observed relative risks.

Replication of findings remains challenging for epigenome-wide association studies, but as costs associated with these assays decrease and the number of studies able to make these measurements in a large number of samples increases, we anticipate that it will become increasingly possible to conduct more definitive replication studies, as has been achieved for common genetic variants via genome-wide association study consortia. 
Conflict of Interest: The authors declare that they have no conflict of interest.

Informed consent: Informed consent was obtained from all individual participants included in the study.

\section{REFERENCES}

1. Tang Q, Holland-Letz T, Slynko A, Cuk K, Marme F, Schott S, Heil J, Qu B, Golatta M, Bewerunge-Hudler M, Sutter C, Surowy H, Wappenschmidt B, Schmutzler R, Hoth M, Bugert P, Bartram CR, Sohn C, Schneeweiss A, Yang R, Burwinkel B. (2016) DNA methylation array analysis identifies breast cancer associated - RPTOR, MGRN1 and RAPSN hypomethylation in peripheral blood DNA. Oncotarget, Aug 26. doi: 10.18632

2. Severi G, Southey MC, English DR, Jung CH, Lonie A, McLean C, Tsimiklis H, Hopper JL, Giles GG, Baglietto L. Breast Cancer Res Treat. 148:665-73. doi: 10.1007/s10549014-3209-y.

3. Dugué PA, English DR, MacInnis RJ, Jung CH, Bassett JK, FitzGerald LM, Wong EM, Joo JE, Hopper JL, Southey MC, Giles GG, Milne RL. (2016) Reliability of DNA methylation measures from dried blood spots and mononuclear cells using the HumanMethylation450k BeadArray. Sci Rep. 6:30317. doi: 10.1038/srep30317. 
TABLE. Replication analysis of the 3 CpG sites identified in Tang et al., Oncotarget, 2016, in the Melbourne Collaborative Cohort Study.

\begin{tabular}{|c|c|c|c|c|c|c|c|}
\hline \multirow[b]{2}{*}{ GENE (CpG site) } & \multirow[b]{2}{*}{ Methylation } & \multirow[b]{2}{*}{ Controls $(\mathrm{N}=\mathbf{4 2 3})$} & \multirow[b]{2}{*}{ Cases $(\mathrm{N}=\mathbf{4 2 3})$} & \multicolumn{2}{|c|}{$\begin{array}{c}\text { Not adjusted for cell } \\
\text { composition }\end{array}$} & \multicolumn{2}{|c|}{$\begin{array}{l}\text { Adjusted for cell } \\
\text { composition }\end{array}$} \\
\hline & & & & $\mathrm{OR}^{\mathrm{a}}(95 \% \mathrm{CI})$ & $\mathbf{P}^{\mathbf{b}}$ & $\mathrm{OR}^{\mathrm{a}}(95 \% \mathrm{CI})$ & $\mathbf{P}^{\mathbf{b}}$ \\
\hline \multirow{8}{*}{$\begin{array}{c}\text { bRPTOR } \\
(\operatorname{cg06418238})\end{array}$} & Median (IQR) Beta-value & $0.36[0.26-0.47]$ & $0.36[0.26-0.47]$ & & & & \\
\hline & Q1 & 106 & 108 & $1.02(0.62-1.70)$ & & $0.98(0.56-1.73)$ & \\
\hline & Q2 & 106 & 108 & $1.02(0.64-1.63)$ & & $0.99(0.59-1.65)$ & \\
\hline & Q3 & 105 & 102 & $0.98(0.63-1.51)$ & & $0.97(0.60-1.55)$ & \\
\hline & Q4 & 106 & 105 & 1.00 (reference) & 0.98 & 1.00 (reference) & 0.99 \\
\hline & & All cases $(\mathrm{N}=423)$ & per $1 \mathrm{SD}$ of M-values & $0.99(0.81-1.20)$ & 0.91 & $1.03(0.81-1.30)$ & 0.83 \\
\hline & & Cases within 5 years $(\mathrm{N}=114)$ & per $1 \mathrm{SD}$ of M-values & $1.04(0.57-1.48)$ & 0.86 & $1.24(0.58-2.13)$ & 0.46 \\
\hline & Interaction M & ylation * Time since blood drav & ontinuous) & $\mathrm{P}=0.63$ & & $\mathrm{P}=0.98$ & \\
\hline \multirow{8}{*}{$\begin{array}{c}\text { MGRN1 } \\
(\operatorname{cg00736299)}\end{array}$} & Median (IQR) Beta-value & $0.44[0.35-0.52]$ & $0.44[0.37-0.52]$ & & & & \\
\hline & $\mathrm{Q} 1$ & 106 & 86 & $0.78(0.45-1.35)$ & & $0.62(0.31-1.25)$ & \\
\hline & Q2 & 106 & 130 & $1.23(0.76-1.99)$ & & $1.06(0.60-1.88)$ & \\
\hline & Q3 & 105 & 101 & $0.99(0.63-1.56)$ & & $0.88(0.53-1.45)$ & \\
\hline & Q4 & 106 & 105 & 1.00 (reference) & 0.20 & 1.00 (reference) & 0.13 \\
\hline & & All cases $(\mathrm{N}=423)$ & per $1 \mathrm{SD}$ of M-values & $0.99(0.81-1.23)$ & 0.96 & $1.12(0.81-1.54)$ & 0.51 \\
\hline & & Cases within 5 years $(\mathrm{N}=114)$ & per $1 \mathrm{SD}$ of M-values & $0.83(0.48-1.29)$ & 0.43 & $0.81(0.34-1.67)$ & 0.57 \\
\hline & Interaction M & ylation * Time since blood drav & intinuous) & $\mathrm{P}=0.65$ & & $\mathrm{P}=0.88$ & \\
\hline \multirow{8}{*}{$\begin{array}{c}\text { RAPSN } \\
(\operatorname{cg27466532})\end{array}$} & Median (IQR) Beta-value & $0.53[0.45-0.61]$ & $0.53[0.46-0.61]$ & & & & \\
\hline & $\mathrm{Q} 1$ & 106 & 94 & $0.99(0.58-1.71)$ & & $0.91(0.46-1.77)$ & \\
\hline & Q2 & 106 & 123 & $1.29(0.78-2.13)$ & & $1.21(0.67-2.17)$ & \\
\hline & Q3 & 105 & 104 & $1.12(0.69-1.80)$ & & $1.05(0.62-1.78)$ & \\
\hline & Q4 & 106 & 101 & 1.00 (reference) & 0.51 & 1.00 (reference) & 0.51 \\
\hline & & All cases $(\mathrm{N}=423)$ & per $1 \mathrm{SD}$ of M-values & $0.93(0.75-1.15)$ & 0.48 & $0.94(0.67-1.31)$ & 0.71 \\
\hline & & Cases within 5 years $(\mathrm{N}=114)$ & per $1 \mathrm{SD}$ of M-values & $0.77(0.50-1.28)$ & 0.25 & $0.64(0.35-1.49)$ & 0.19 \\
\hline & Interaction $\mathrm{M}_{\mathrm{c}}$ & ylation * Time since blood drav & ontinuous) & $\mathrm{P}=0.36$ & & $\mathrm{P}=0.66$ & \\
\hline
\end{tabular}

\footnotetext{
${ }^{\mathrm{a}}$ Conditional logistic regression models comparing cases to controls matched on age, ethnicity, year of baseline attendance, year of blood draw, sample type, and Illumina Infinium HumanMethylation 450K methylation assay batch;

${ }^{\mathrm{b}}$ For the analyses using methylation quartiles, the p-value corresponds to a likelihood ratio test (Chi-square with 3 degrees of freedom) comparing the models with and without the quartile variable

$\mathrm{IQR}$, inter-quartile range; SD, standard deviation
} 